\title{
Estudos de gênero e psicanálise: diálogo possível
}

Gender studies and psychoanalysis: a possible dialogue

\author{
Jacqueline Virmond Vieira \\ Universidade Federal de Santa Catarina, Brasil \\ jacquievv@gmail.com
}

Mara Coelho de Souza Lago

Universidade Federal de Santa Catarina - Universidade Estadual de Campinas, Brasil

mara.lago@ufsc.br

\section{Resumo:}

Neste artigo, procuramos mostrar que é possível estabelecer um diálogo crítico e frutífero entre teóricas dos estudos feministas e de gênero e a psicanálise freudo-lacaniana, trazendo para o texto concepções de Judith Butler, Gayle Rubin e Márcia Arán. Estas autoras foram escolhidas por suas contribuições destacadas a esse diálogo, pois refletem sobre novas formas de relacionamentos, estilos de vida, sexualidades, identidades culturais, com seus consequentes e contemporâneos modos próprios de subjetivação e mal estar na cultura, valendo-se de e questionando pressupostos da psicanálise em seus estudos. Palavras chave: psicanálise; feminismos; gênero; sexualidades; identidades.

Palavras-chave: Psicanálise, Feminismos, Gênero, Sexualidades, Identidades.

\section{Abstract:}

In this article, we intended to demonstrate that it's possible to establish critical and productive dialogue between feminist and gender studies and Lacanian/Freudian psychoanalysis, bringing to the text conceptions by Judith Butler, Gayle Rubin and Márcia Arán due to outstanding contributions to the dialogues. These authors reflect on new forms of relationships, lifestyles, sexualities, cultural identities and contemporaneous ways of subjectivation and discontents in culture, sometimes supporting their studies on the assumptions of psychoanalysis, sometimes questioning psychoanalysis.

KEYWORDs: Psychoanalysis, Feminisms, Gender studies, Sexualities, Identities.

\section{INTRODUÇÃO ${ }^{1}$}

Nosso objetivo neste artigo foi estabelecer um diálogo entre teóricas de gênero e a psicanálise freudolacaniana, de modo que se pudesse verificar alguns pontos de parceria interdisciplinar e pontos de desencontro. Tratando-se de um campo vasto, o dos estudos feministas e de gênero, selecionamos três autoras que estabelecem relações importantes com a psicanálise e, a partir de uma metodologia que privilegia o aspecto historiográfico, percorremos algumas obras destas autoras e também algumas entrevistas nas quais elas falam sobre seus liames com a psicanálise. A escolha dos textos psicanalíticos que sustentam nossas articulações foi orientada com base nas temáticas e conceitos psicanalíticos abordados pelas autoras.

As autoras com quem buscamos dialogar são a antropóloga estadunidense Gayle Rubin, a filósofa americana Judith Butler e a psicanalista brasileira Márcia Arán, escolhidas por suas contribuições em interlocuções com a psicanálise, às vivências/relações de gênero no contemporâneo. 


\section{GÊNERO, PSICANÁLISE E FEMINISMOS}

Gênero é uma palavra que adquiriu o status de significante mestre na cultura, aquele que organiza uma série de discursos e enquanto discurso, produz laços sociais. Nos últimos anos, a categoria gênero passou a estar intensamente associada, de acordo com Marie-Hélène Brousse (2016), às questões de identidades e minorias. Pode-se dizer que muitos movimentos sociais da atualidade têm em sua base movimentos importantes que adquiriram visibilidade no século passado, os movimentos feministas que irromperam com a intensidade de uma segunda onda na Europa e nos Estados Unidos e em movimentos de reinvindicação de igualdade entre homens e mulheres, colocando em questão a suposta naturalidade das diferenças de direitos. Ainda que não constituíssem uma unidade em pensamento e militância, partilhavam algumas ideias centrais persistentes, como a de que as mulheres ocupam lugares sociais inferiores, estão em posição de subordinação em relação aos homens, e que esta subordinação é construída socialmente.

De acordo com Patrícia Porchat (2014), a primeira utilização da palavra gênero, para além do tradicional uso gramatical ou no campo da biologia, foi feita pelo psicanalista Robert Stoller em 1964. Este autor introduziu uma distinção entre a palavra "sexo", como referida às características biológicas que diferenciam homens e mulheres, e a palavra "gênero", referida às características culturais de diferenciação entre estes/as. Mas segundo Adriana Piscitelli (2018), foi a partir da publicação, em 1975, do ensaio $O$ tráfico das mulheres: Notas sobre a economia politica do sexo de Gayle Rubin (1993), que o termo adquiriu um peso significativo na cultura. $\mathrm{O}$ termo gênero foi adotado amplamente por representar possibilidades analíticas mais abrangentes que as oferecidas pela categoria mulher.

Muito antes que a palavra gênero tomasse a dimensão que tem hoje, os debates entre psicanálise e feminismos já tinham lugar.

"Os feminismos e a psicanálise, como discursos que se articularam a partir dos finais do século XIX e se constituíram como movimentos (d)e pensamentos em diferentes momentos de elaboração e atuação por todo século XX, não foram estranhos desde sempre, mesmo que suas relações tenham sido marcadas por desencontros, polêmicas, oposições. Relações ambivalentes que continuam se fazendo na atualidade" (Lago, 2010, p. 287).

Como poderemos ver, estas relações ambivalentes entre a psicanálise e os estudos de gênero seguem tendo lugar. Judith Butler (2003), conhecida e respeitada autora dos gender studies, tem tido uma relação particularmente importante com a psicanálise. Em contrapartida, a autora encontra um lugar destacado nas discussões psicanalíticas, principalmente no âmbito da psicanálise freudo-lacaniana, aqui no Brasil, na Europa e em outros países latino-americanos como Colômbia e Argentina. A psicanalista Patrícia Porchat Knudsen entrevistou Butler na França em 2008. É desta entrevista, publicada na Revista Estudos Feministas (2010), que retiramos uma parte na qual Butler fala de suas relações com a psicanálise:

\footnotetext{
"Para mim é uma teoria muito importante, uma prática muito importante. Estou envolvida com suas tradições, com sua teoria, quanto a isso não há dúvida. Mas sinto também que ela precisa ser posta em contato coma a Teoria Cultural e a Política Cultural, de um modo mais geral. Então eu me vejo arranjando um encontro ou alguma espécie de reunião entre psicanálise e movimentos sociais mais amplos, políticas culturais e questões relativas a gays, lésbicas, bi, trans, intersexo. Preocupa-me o fato de que tantas pessoas nesses movimentos resistam à psicanálise, que julguem que a psicanálise não é mais do que regulação social, normalização. E por outro lado os psicanalistas resistem de verdade a isso, acham que estão trabalhando numa esfera completamente separável da psique, que esta é autônoma, que segue suas próprias regras, como se o que acontece no interior da transferência fosse algo isolado do que ocorre no mundo exterior. Acho que esse não é um antagonismo necessário, porque a psicanálise pode fornecer uma crítica vigorosa da normalização, uma crítica vigorosa da regulação social, pode nos proporcionar uma teoria da fantasia, pode colocar em questão o corpo natural, pode observar o modo como o poder social toma forma na psique, há várias maneiras de se fazer isso. E acho que os movimentos sociais preocupados com isso podem entender melhor sua própria situação a partir de uma perspectiva psicanalítica. E talvez até desenvolver vocabulários mais complexos para pensar a identidade, ou o desejo, ou a solidariedade, três conceitos essenciais para esses movimentos" (Butler a Knudsen, 2010, p. 166-167).
} 
A importância política dos estudos de gênero tem sido dar visibilidade aos sofrimentos causados pelas exigências da cultura patriarcal no enquadramento das pessoas em determinados padróes de sexualidade, de relações amorosas e eróticas. Padrões que obrigavam as pessoas a esconder ou deformar seus comportamentos, suas manifestações e seus desejos relacionados à sexualidade. Eduardo Saraiva (2007) entrevistou alguns homens, que por não poderem assumir seus desejos homossexuais temendo os sentimentos de inadequação, as censuras e a ridicularização, assumiram comportamentos esperados de homens em suas sociedades, constituindo famílias heterossexuais, tendo filhos, para só mais tarde, após processos psicoterápicos (em alguns casos), assumirem seus desejos de relacionar-se sexual e amorosamente com outros homens.

Os estudos de gênero têm demonstrado como determinadas normas que regulam como o devem ser homens e mulheres, ficaram tão cristalizadas que foram tomadas como naturais, e não como tendo sido construídas socialmente. Os gender studies apontaram posturas preconceituosas e marginalizantes, tornando-se porta-voz de muitos que se sentiam excluídos do acesso a seus direitos de justiça e cidadania. Estes estudos, que apoiam e subsidiam movimentos militantes de direitos de gênero, têm exercido um papel fundamental nas mudanças observadas nas relações entre identidade, sexo e desejo na atualidade.

\section{Gayle Rubin vê a psicanálise como uma teoria feminista manQué}

Gayle Rubin (2003) conta, em uma entrevista concedida a Judith Butler publicada em Cadernos Pagu, que seu ensaio de 1975 Tráfico de Mulheres: notas sobre a "economia politica" do sexo originou-se durante a segunda onda de feminismo, fins da década de 1960, quando se buscava compreender as causas da opressão das mulheres. Ela explica que na época o paradigma para a compreensão dos fenmenos sociais era o marxismo o qual, entretanto, não dava conta de explicar as diferenças de gênero e sexualidade. Segundo ela, o marxismo oferecia possibilidades de uma compreensão precária das questões de gênero e "tinha limitações intrínsecas como estrutura teórica para o feminismo" (Rubin com Butler, 2003, p. 6), num momento em que era necessário buscar uma base teórica para o lesbianismo. A análise das relações de classes tratava do humano, não realizando nenhum tipo de recorte nas particularidades da problemática homem-mulher. Para responder a questôes necessárias ao estudo do que conceituou como sistema sexo-gênero, Rubin recorreu a textos que lhe chegavam às mãos naquele momento, como As Estruturas Elementares de Parentesco de Claude Lévi-Strauss (1969) e artigo de Louis Althusser (1969) sobre Freud e Lacan. A partir deste artigo de Althusser, Rubin se aproximou da psicanálise e nela descobriu uma ferramenta para tentar resolver determinados problemas relacionados a sexo-gênero. Segundo a autora, neste momento era muito restrito o acesso nos Estados Unidos aos textos de Lacan. Havia apenas traduções de dois artigos de Lacan, dentre os quais Função e Campo da Palavra em Psicanálise (1968) e alguns outros sobre as teorias de Lacan. Percebendo uma relação entre LéviStrauss e Lacan, nesta fase estruturalista, Rubin busca sustentação nestes autores, além de Freud, para escrever seu ensaio Tráfico de Mulheres, de 1975.

Em Lévi-Strauss ela encontra argumentos que sustentam que a sexualidade nunca tem o caráter de natural, em quaisquer que sejam os arranjos humanos. "Todas as formas de sexo e gênero são tomadas como sendo instituídas pelos imperativos dos sistemas sociais" (Rubin, 1975, p.11). Isto é, a divisão de gêneros é socialmente imposta. Inclusive o que significa ser homem e ser mulher é socialmente determinado e independe, na verdade, do sexo biológico. Exemplifica com o sistema de parentesco dos Azande da África Central, no qual as mulheres eram preferencialmente destinadas aos homens mais velhos, os homens mais jovens escolhem meninos e os convertem em suas esposas, pagando o preço do dote prescrito para obter uma noiva. Menciona ainda outro sistema no qual a mulher podia se tornar marido se possuísse o necessário para pagar o dote (Rubin, 1975, p. 12). Segundo Rubin, existem normas de divisão de gênero que implicam coercitivamente em definições de como devem ser os comportamentos e personalidades masculinos e femininos. Igualmente, em todos esses casos, verifica-se que aquele que é designado mulher comparece como 
objeto de permuta e preferencialmente com uma posição social e sexualmente passiva: desejada, negociada. Casos que evidenciam que a definição de homem ou mulher não está pautada no sexo biológico.

Gayle Rubin conclui que algumas generalidades básicas na organização da sexualidade se repetem nos mais diversos sistemas de parentesco: o tabu do incesto, a heterossexualidade obrigatória e uma divisão assimétrica dos sexos. Constatando que é necessário compreender como estas regras se subjetivam nas crianças e se perpetuam, a autora vai recorrer à psicanálise. Comenta os embates entre a psicanálise e os feminismos, dizendo que nos Estados Unidos isso se deve em parte à americanização da psicanálise, que distorceu seus princípios subversivos. A peste freudiana, num país no qual o sucesso pessoal era o bem supremo, e a adequação o mais esperado, a psicanálise perdeu seu potencial revolucionário, harmonizou-se com os parâmetros oficiais de normalidade e perdeu o caráter de "cifra única do destino de cada um" (Cesarotto \& Leite, 1993, p. 25). As feministas também não viam com bons olhos as teorizações da inveja do pênis e a centralidade do falo. Rubin, entretanto, tinha outra posição em relação à psicanálise:

"É uma teoria da sexualidade na sociedade humana. De forma mais importante, a psicanálise oferece uma descrição dos mecanismos pelos quais os sexos são divididos e deformados, de como bebês bissexuais, andrógenos são transformadas em meninos e meninas. A psicanálise é uma teoria feminista manquée" (Rubin, 2017, p.14).

Rubin afirma que a concepção inicial freudiana de um Complexo de Édipo no menino e um correlativo Complexo na menina, pressupunha diferenças pautadas num imperativo biológico da heterossexualidade. O menino desistia da mãe por temor da rivalidade paterna; a menina desistia do pai por temer a vingança materna. Com a concepção psicanalítica de uma fase pré-edipiana, na qual todas as crianças teriam como primeiro objeto a mãe, ocorreu um deslocamento deste pressuposto biológico. "Na fase pré-edipiana, crianças de ambos os sexos seriam consideradas indistinguíveis do ponto de vista psíquico, o que significaria que sua diferenciação em crianças do sexo masculino e feminino, tinha que ser explicada, e não tomada como dada" (Rubin, 2017, p. 38). Todas as crianças possuíam inicialmente um amplo espectro de possibilidades libidinais ativas e passivas. No caso das mulheres o processo era ainda mais complexo, pois seu primeiro objeto era a mãe e dirigiam a ela uma sexualidade ativa, logo teriam que mudar de objeto -da mãe para o pai- e de posição - de uma sexualidade ativa para uma passiva-. Rubin cita Freud: "É próprio da peculiaridade da psicanálise, então, que ela não se ponha a descrever o que é a mulher (...) mas investigue como a mulher vem a ser, como se desenvolve a partir da criança inatamente bissexual” (Freud, 2010 [1933], p. 38).

Rubin menciona que os conceitos freudianos de inveja do pênis ${ }^{2}$ e castração deixam as feministas enfurecidas. Principalmente a partir de sua afirmação de que é a partir do reconhecimento da castração materna que a menina abandona a mãe como objeto. Comenta que isto pode ser lido como uma afirmação de que a feminilidade é consequência da diferença anatômica dos sexos, mas que considera esta uma leitura equivocada. Entende que Freud afirmava que a sexualidade adulta era consequência do desenvolvimento psíquico, e não biológico. Como vemos, Rubin encontra na psicanálise freudiana uma via de apreender as lógicas de constituição da sexualidade e das identidades de gênero, embora a considere uma teoria feminista incompleta, por não conseguir relacionar a variação sexual sem tornar-se reducionista (Porchat, 2014).

Ao comentar a teorização lacaniana, com o cuidado e com o rigor que lhe é peculiar, Rubin inicia ressaltando que Lacan distingue um pai, o homem, da função de pai, assim como faz uma distinção radical entre pênis, o órgão, e o falo, símbolo. O falo tem um valor simbólico, que indica uma posição subjetiva, que não guarda relação com a biologia, afirma ela. Ter ou não ter o falo, são duas posições simbólicas possíveis. Apreende também que castração não é uma falta real, mas um significado atribuído aos genitais da mulher (Rubin, 2017). O Complexo de Édipo é uma expressão das trocas fálicas interfamiliares. Segundo Rubin, o falo é, e aqui entendemos que ela se refira a portar o falo, a personificação do status masculino

"[...] com o qual os homens consentem, e do qual certos direitos são parte inerente - entre outros, o direito a uma mulher (...) É transmitido através das mulheres e se estabelece entre os homens. Alguns dos rastros que deixa são a identidade de gênero 
e a divisão dos sexos. Mas ele deixa mais que isto. Deixa também a 'inveja do pênis', que se torna bastante significativa do desconforto das mulheres em uma cultura fálica" (Rubin, 2017, p. 44).

De acordo com Patrícia Porchat (2014) Rubin restitui a credibilidade da psicanálise no feminismo americano, mostrando que a psicanálise fornece um corpo teórico que permite conceber a construção das identidades de gênero e afastando a ideia de que a psicanálise reforça os padrões heteronormativos da sexualidade.

Ainda neste ensaio, Rubin, demonstrando a sutileza de suas reflexões, diz que não apenas as mulheres são oprimidas, os homens também o são por terem que ser homens. Entende que o movimento feminista deveria sonhar com mais que o fim da opressão das mulheres, deveria sonhar com a eliminação das sexualidades obrigatórias e dos papéis sexuais obrigatórios; deveria sonhar, enfim, com uma sociedade andrógena. Estaríamos chegando próximos da realização deste sonho de Rubin na contemporaneidade?

Uma vez que, para Rubin, a psicanálise não daria conta de pensar as variabilidades da sexualidade, é no intuito de trabalhar esta variabilidade que Rubin escreve Thinking Sex. Na entrevista já mencionada, que concedeu a Butler em 1994, 19 anos depois de haver publicado a versão final de Trafico de Mulheres, Rubin conta que nos anos de 1970 havia a expectativa de que mudando as configurações de parentesco no social, poder-se-ia sair do sistema heterossexual binário. Entretanto, o que aconteceu é que as pessoas se deram conta de que não era tão simples livrar-se de certas conservas culturais, que as suas psiques haviam sido formadas havia muito tempo e eram refratárias a uma mudança rápida das relações sociais e de parentesco. A psicanálise diz que há algo intratável no simbólico e, em sua conversa com Butler, Rubin se interroga se esse intratável seria a linguagem, a estrutura da linguagem. E, ao constatar que para Lacan a diferença sexual esta correlacionada à própria linguagem e sendo a linguagem um sistema binário de oposições, afirma ela na entrevista: "Há algo intrinsecamente problemático em qualquer ideia de que, em certa medida, a própria linguagem ou a capacidade para adquiri-la requer uma diferenciação sexual enquanto diferenciação principal” (Rubin a Butler, 2003, p. 166).

Rubin entende que seria necessário buscar outro instrumental teórico, porque, segundo sua compreensão, com Lacan não haveria como sair do sistema binário para pensar a sexualidade a partir de uma ferramenta que acolhesse o sistema sexo/gênero para além do binarismo. Thinking Sex surge num momento em que tentava se afastar do estruturalismo, orientando-se por modelos pós-estruturalistas ou pós-modernistas.

"Mesmo a ideia de um continuum não é um bom modelo para as variações sexuais; é necessário um desses modelos matemáticos que agora se fazem, com topologias estranhas e formas convolutas. É preciso haver um modelo que não seja binário, porque a variação sexual é um sistema de muitas diferenças, não apenas um par de diferenças conspícuas" (Rubin a Butler, 2003, p. 168).

É interessante observar aqui que o próprio Lacan se desloca do estruturalismo em suas teorizações, apoiando-se em um modelo topológico nos anos finais de seu ensino, conhecidos como a clínica do Real. ${ }^{3}$ Essa nova maneira de pensar a psicanálise, a partir dos anos 1970, vai se sustentar na topologia, de modo que as diferentes constituições subjetivas dependem de modos singulares de enodamento dos registros do Imaginário, Simbólico e Real. Segundo Patrícia Porchat (2014) Rubin teria tido acesso apenas a uma pequena parte da vasta obra de Lacan.

Rubin entendia que a psicanálise na abordagem da variação sexual, às quais se refere como perversões, era muito reducionista (Rubin a Butler, 2003). O movimento feminista também era reducionista no que se referia às variações sexuais. Diz ela:

"Transexualismo, homossexualismo masculino, promiscuidade, sexo público, travestismo, fetichismo e sadomasoquismo - tudo isso era condenado pela retórica feminista, e se atribuía a cada um deles certa responsabilidade na criação e na manutenção da subordinação das mulheres" (Rubin a Butler, 2003, p. 179).

Ou seja, o próprio movimento das feministas radicais, representado por Catherine MacKinnon, condenava uma série de práticas sexuais "desviantes”, acusando-as de serem práticas que reforçavam o 
patriarcalismo. A psicanálise, não contribuía muito para pensar e legitimar estas práticas, uma vez que, aos olhos de Rubin, a psicanálise focava sua atenção na questão individual e não no social.

Rubin propunha o questionamento da heteronormatividade e a abertura às sexualidades marginais também como uma via para, aproveitando o potencial subversivo destas sexualidades excluídas, questionar a ordem social e política instituída. Ela voltou a ler os textos freudianos sobre sexualidade, como os Três ensaios sobre a teoria da sexualidade (2010 [1905]), e concluiu que os escritos freudianos sobre as aberrações sexuais eram interessantes, mas limitados. Haviam sido escritos num momento em que floresciam muitos outros escritos relevantes sobre a sexualidade na Europa. Concluiu que talvez Freud se interessasse mesmo era pelos neuróticos, o que de fato era verdade, pois raramente a perversão aparecia na clínica, exceto pela via do neurótico e suas fantasias. Acabou deixando a psicanálise de lado e foi buscar outra maleta de ferramentas em Michel Foucault (1988), a quem conhecera numa biblioteca em Paris, quando já havia sido capturada por sua História da Sexualidade.

"A história da sexualidade de Michel Foucault (1978) tem sido o mais influente e emblemático texto do novo conjunto de reflexões sobre o sexo. Foucault critica o entendimento tradicional da sexualidade como impulso natural da libido para se liberar da coerção social. Ele argumenta que os desejos não são entidades biológicas preexistentes, mas, em vez disso, são constituídos no decorrer de práticas sociais específicas ao longo da história. Foucault enfatiza mais os aspectos da organização social do sexo que seus elementos repressivos, ressaltando que novas sexualidades são constantemente produzidas. E ele assinala uma grande descontinuidade entre os sistemas de sexualidade baseados no parentesco e outros mais modernos" (Rubin, 2012, p.12).

Ainda em Pensando o Sexo, Rubin vai apresentar uma hierarquização de práticas sexuais que são socialmente classificadas indo do bom sexo ao mau sexo.

\begin{abstract}
"De acordo com esse sistema, a sexualidade "boa", "normal", e "natural" deve idealmente ser heterossexual, marital, monogâmica, reprodutiva e não comercial. Ela se daria entre casais, dentro da mesma geração e em casa. Ela não envolveria pornografia, objetos de fetiche, brinquedos sexuais de nenhum tipo, ou quaisquer outros papéis que não fossem o masculino e o feminino. Qualquer forma de sexo que viole essas regras é "má", "anormal" ou "não natural". O sexo mau pode ser homossexual, o que acontece fora do casamento, promíscuo, não-procriador ou comercial. Pode ser a masturbação, as orgias, o casual, o que cruza fronteiras geracionais e que se pratica em lugares "públicos", ou ao menos em arbustos ou em banheiros, moitas ou saunas. Pode envolver o uso de pornografia, objetos de fetiches, brinquedos sexuais, ou papéis pouco usuais" (Rubin, 2012, p. 17-18).
\end{abstract}

Ela vai dizer que estas categorizações estão mais relacionadas a uma ideologia racista do que a uma ética. Uma ética tomaria em consideração aspectos outros: como os parceiros se tratam, se os parceiros oferecem prazeres uns aos outros, a presença ou não de mútuo consentimento e assim por diante.

Rubin teve uma relação muito importante com a psicanálise e para a psicanálise. Com seus ensaios e artigos influenciou uma geração de feministas e militantes de gênero na utilização da psicanálise, principalmente a partir de seu Tráfico de Mulheres, como uma teoria importante para a compreensão da subjetivação das normas de gênero, não sem deixar claro que a psicanálise (ao menos a que ela conhecia) era útil, mas não suficiente.

\title{
4. Judith Butler: A PSicANÁlise COMO FERRAMENTA PARA A COMPREENSÃo dos MECANISMOS PSÍQUICOS DA SUBMISSÃO
}

Judith Butler, em suas relações com a psicanálise, vai implicar a problemática de gênero com a constituição subjetiva. Em seu livro Mecanismos psíquicos del poder: teorías sobre la sujeción (2001), ${ }^{4}$ Butler afirma que a submissão, enquanto modalidade de poder, é paradoxal, pois uma das formas mais conhecidas de submissão consiste em ser dominado por um agente externo. Entretanto, com Foucault, Butler aprendeu que o poder é algo que participa da própria constituição do sujeito, imprescindível para sua existência, bem como para a trajetória de seu desejo. Logo, o poder não é simplesmente algo a que podemos 
nos opor, mas é também algo de que o sujeito depende para sua existência e que abriga no seu próprio ser. Vemos aqui que Butler comunga com Freud e Lacan em certos aspectos de suas proposições da constituição subjetiva. Afinal, tanto nas teorias freudianas do Édipo com a identificação às insígnias do pai, que redunda no surgimento do Ideal do eu e no supereu, quanto nos ensinamentos lacanianos, seja na releitura do Édipo a partir do significante Nome-do-pai, ou nos processos lógicos de alienação e separação que ele trabalha em Posição do Inconsciente (Lacan, 1998 [1964]), ${ }^{5}$ a alienação ao Outro é condição necessária à estruturação da subjetividade.

O que podemos verificar é que Butler não se ilude que as exigências que constringem a identidade e a vida sexual se resumam àquelas que partem do meio social, considerando também as que se originam no psiquismo de cada um. Para Butler (2001) o poder não só incide no momento de formação do sujeito, mas é, a partir de então, reiterado na própria atuação do sujeito. Isto leva Butler a se perguntar como adotar uma atitude de oposição ao poder, se toda a oposição está comprometida subjetivamente com o poder a que se opõe. $\mathrm{E}$ se o sujeito é obrigado a buscar o reconhecimento de sua própria existência em categorias, nomes, etc, que não criou, ou seja, é obrigado a buscar os signos de sua existência fora de si, isto "impone una vulnerabilidad primaria ante el Otro como condición para alcanzar el ser” (Butler, 2001, p. 32). Embora este Outro com maiúscula nos faça pensar em Lacan, não fica claro se é este o conceito que Butler utiliza na frase acima. Ao longo deste texto, a autora faz menções às proposições de formação do sujeito de Foucault, Freud, Lacan, dentre outros autores, e nem sempre esclarece a que autor se refere em determinado momento. ${ }^{6}$ Ela segue discutindo a submissão a partir de algumas articulações com a noção de melancolia em Freud e Melanie Klein, apontando a identificação ao outro perdido e o medo de destruir o outro com sua própria agressividade como processos que contribuem para que a possibilidade de revolta se neutralize. E explica que seu interesse se deve a pensar que compreender esses impasses a que conduzem certos esforços de emancipação seria uma possibilidade de fazer frente ao poder que submete.

No capítulo intitulado Sometimentos posthegelianos, Butler discute os imperativos morais, produzidos como retorno da repressão das satisfações libidinais reprimidas: " la libido no es negada del todo por la represión, sino que, más bien, se convierte en el instrumento de su propio sometimiento” (Butler, 2001, p. 66). Aqui fala da face insensata do superego freudiano, que se alimenta dos impulsos reprimidos e redunda nos imperativos superegóicos de gozo.

Butler aposta na resistência inconsciente como uma saída, e se pergunta se com Lacan não se poderia pensar num domínio psíquico que resistisse à legibilidade. Parece que, sem ter clareza sobre concepções de Lacan, Butler intui que nem tudo pode ser tomado pela cadeia significante, que algo escapa. Aposta nisto como a possibilidade de fugir à consistência simbólica de uma identidade sexuada. E, para fundamentar esta concepção, cita a psicanalista lacaniana Jacqueline Rose, que afirma haver uma resistência à identidade no centro da vida psíquica (Butler, 2001).

Butler vai fazer uma articulação entre a melancolia e o gênero, a partir do artigo Luto e Melancolia de Freud (1976 [1917]). Vai argumentar que o gênero não se estabiliza justo porque é adquirido mediante o repúdio de vínculos homossexuais. Isto é, a menina se converte em menina ao submeter-se à proibição que exclui a mãe como objeto de desejo e instala o objeto excluído como parte do eu, como uma identificação melancólica. Parece que alude aqui ao processo de identificação ao objeto rechaçado. E afirma:"Por consiguiente, la identificación lleva dentro de sí tanto la prohibición como el deseo” (Butler, 2001, p. 151).

Neste texto, no qual mergulha buscando encontrar saídas para o maior algoz que é a própria subjetividade enquanto produtora de movimentos de submissão, Butler se destaca das usuais posições queixosas encontradas em alguns feminismos e outros movimentos de minorias. Reconhece que cada um involuntariamente contribui para ser colocado em posições que, muitas vezes, se opõem ao que seria o desejo autêntico. Reconhece a implicação de cada sujeito nos assujeitamentos dos quais padece. Também Butler encontra na teoria freudiana das pulsões uma via para pensar a sexualidade para além de rótulos de gênero. Como conta na entrevista já mencionada: 
“(...) O ensaio de Freud A pulsão e suas vicissitudes (Trieb und ibre Schicksale) foi muito importante para mim desde que eu tinha 22 anos. E penso que ali ele introduz a ideia da pulsão como conceito-limite, existindo no limiar entre corpo e ideia ("soma" e ideia). E julgo isso extremamente interessante. A pulsão nunca é plenamente capturada pelas ideias, nem tampouco é plenamente redutível a um corpo biológico, mas existe no ponto de sobreposição entre eles, e Freud chega a dizer que a pulsão é parte dessa linguagem figurativa, é parte da poesia dele” ( Butler a Porchat Knudsen, 2010, p. 166).

A ideia de que as pulsões não estão vinculadas à reprodução, mas a outras satisfações, encanta Butler, que vê nesta teorização elementos para a construção de seus argumentos que visam subsidiar o abandono de articulações tradicionais dos laços binários patriarcais. Podemos hipotetizar que este encontro com a psicanálise tenha sido fundamental para que Butler viesse a construir algumas de suas teorizações, sempre sustentadas em objetivos políticos de reduzir o mal-estar gerado pelas exigências de adequação às normas da sexualidade. Parece-nos que a busca de Butler tem analogias com o que se espera de um processo de análise, desalienação ao Outro e possibilidades de saber fazer de acordo com os modos de gozo e desejo que habitam a cada um.

Em seu livro Problemas de gênero (2003) Butler vai argumentar que as normas binárias heteronormativas de sexo e gênero, além de produzirem efeitos de nomeação de gênero, definem características anatomofisiológicas, modalidades de desejo e práticas sexuais que devem estar em consonância com aquelas nomeações. E aqueles que escapam a esta normatização constituem o que ela nomeia de gêneros ininteligíveis, que não são visíveis e reconhecidos. Esta invisibilidade cria um problema a mais, faz com que estes gêneros sejam classificados como patológicos. Influenciada por sua leitura de Foucault, Butler vai interpretar que há uma matriz identitária a partir da qual se medem as adequações e inadequações e se classificam as normalidades e patologias. Esta matriz identitária é heterossexual. É uma matriz discursiva que se assenta na ritualização de atos repetidos que produzem como efeito dar a ilusão de consistência ontológica à dicotomia de gênero, que produziria homens e mulheres. Uma das possibilidades é a repetição sob a forma de paródia, como no caso de uma drag queem que imitaria uma mulher, dando a impressão de que haveria alguma consistência ou substância no modelo, isto é no ser mulher. Esta suposição de uma consistência ontológica do homem e da mulher é o que faz com que cada um que não se adeque a esta suposta consistência sofra com sentimentos de ser marginal à norma. E é neste ponto que Butler começa a se opor a Lacan, pois entende que se apoia numa matriz heterossexual para pensar a construção das identidades sexuais. Se ela entendia que em Freud não havia consonância entre desejo, gênero, sexo e práticas sexuais, em Lacan vai reconhecer a concepção de uma matriz heterossexual na releitura do Édipo freudiano. Lacan realmente fala em virilização do homem e feminização da mulher. A teorização de Lacan que atribui ao falo o valor de significante universal em relação ao qual as identificações se distribuem em ser o falo ou ter o falo, também são criticadas por Butler. Ela contesta esta concepção, por entender que operaria reforçando a matriz heteronormativa da identidade sexual.

Acreditando que na base da construção teórica do complexo edipiano reside uma matriz heterossexual, Butler (2003) vai recorrer aos textos freudianos Luto e Melancolia (1976 [1917]) e OEgo e o Id (1976 [1923]) para fundamentar sua tese. Comenta que Freud isola o mecanismo da melancolia, referindo a identificação ao objeto perdido, caracterizando-o como crucial na construção do caráter e do ego, mas não refere suas relações com a identidade de gênero. "A perda do outro desejado e amado é superada mediante um ato específico de identificação, ato este que busca acolher o outro na própria estrutura do eu" (Butler, 2003, p. 90). Esta identificação não é momentânea, mas vai estruturando o caráter e também condicionando a aquisição de uma identidade de gênero. Butler faz esta afirmação apoiando-se nos ditos de Freud de que "é possível que essa identificação seja a única condição sob a qual o Id pode abrir mão de seus objetos” (Freud, 1976 [1917]) e também que "o caráter do ego é um precipitado de investimentos objetais abandonados e contém a história dessas escolhas de objeto” (Freud, 1976 [1923]). É a série de objetos de amor renunciados a cujos traços ocorrem identificações que corroborariam para a formação da identidade de gênero. $\mathrm{O}$ tabu do incesto seria responsável pela perda de um objeto de amor, o qual seria recuperado por sua internalização. E, ainda segundo 
Butler, em caso de união heterossexual interditada, o objeto é proibido, mas não a modalidade de desejo (heterossexual), logo o desejo é deslocado deste objeto para outro igualmente do sexo oposto. Entretanto, no caso de uma união homossexual e incestuosa, seria necessário renunciar à modalidade de desejo e ao objeto.

Butler comenta as discussões freudianas e cita as dúvidas de Freud quanto à origem do que nomeia masculinidade e feminilidade, ora tratando-os como predisposições, ora como efeitos das rivalidades edípicas. De qualquer modo, Butler chama a atenção para o fato de que Freud tome o desejo pelo pai como uma predisposição feminina, e afirma que esta qualificação acontece porque ele parte de uma matriz heterossexual do desejo. Vejamos o que diz:

“A conceituação da bissexualidade em termos de predisposições, feminina e masculina, que tem objetivos heterossexuais como seus correlatos intencionais sugere que, para Freud, a bissexualidade é a coincidência de dois desejos heterossexuais no interior de um só psiquismo" (Butler, 2003, p. 95).

Butler afirma que, para Freud, a predisposição masculina nunca se orienta do menino para o pai, porque se assim se orientar já será qualificada de predisposição feminina. Por outro lado, a menina quando repudia a mãe enquanto objeto do amor sexual, repudia sua masculinidade e fixa sua feminilidade. A autora conclui, então, que não existe homossexualidade na tese de bissexualidade primária de Freud, "só os opostos se atraem" (Butler, 2003, p. 96). E acrescenta a consideração de que o próprio Freud manifesta suas dúvidas sobre o que seria uma predisposição feminina ou uma predisposição masculina, como vemos na citação que segue: "Significativamente, Freud admite sua confusão sobre o que é exatamente uma predisposição masculina ou feminina, ao interromper sua reflexão a meio caminho com uma dúvida entre travessões: 'o que quer que seja isso -'” (Butler, 2003, p. 95).

Judith Butler vai demonstrar sua concepção de que estas predisposições são efeitos ou produtos de sucessivas identificações. Retoma a argumentação freudiana de que, a partir de O Ego e o Id (1976 [1923]), a identificação melancólica não é mais caracterizada por ele como distinta do processo de luto, mas como a única possibilidade de o id renunciar aos objetos de amor. A renúncia aos objetos amados passa a ser uma condição do processo de luto, seria a preservação do investimento no próprio eu. As perdas internalizadas são constituintes do Ideal do eu, este agente escrutinador moral que Freud não distingue claramente do supereu. O Ideal do eu serve assim como agência interna de sanção e tabu, o qual, segundo Freud, atua para consolidar identidades de gênero por meio da reorientação e sublimação apropriadas do desejo. A internalização do genitor como objeto amoroso sofre uma inversão necessária de sentido. "O genitor não só é proibido como objeto amoroso, mas é internalizado como objeto de amor proibidor ou impeditivo" (Butler, 2003, p. 98). Quer dizer que, ao mesmo tempo em que o Ideal do eu inibe a expressão do desejo por este genitor, fundase um espaço internalizado onde se preserva o amor por este genitor. O Ideal do eu, enquanto este agente de sanções e tabus regula e determina as identificações masculinas e femininas.

Como consequência, as predisposições (feminina e masculina) não são fatos sexuais primários do psiquismo, mas efeitos produzidos por uma lei imposta pela cultura e pelos atos cúmplices e transvalorizadores do ideal de ego. Na melancolia, o objeto amado é perdido por uma variedade de meios: separação, morte ou ruptura de um laço afetivo. Na situação edipiana, contudo, a perda é ditada por uma proibição acompanhada de um conjunto de punições (Butler, 2003, p. 99).

Para Butler é uma diretriz moral apoiada numa matriz heterossexual, ou seja, que se estrutura a partir de um tabu externo, o que está na origem do conflito edipiano. O tabu contra a homossexualidade seria anterior ao tabu heterossexual do incesto. "O menino e a menina que entram no drama edipiano com objetivos incestuosos heterossexuais já foram submetidos a proibições que os 'predispuseram' a direções sexuais distintas" (Butler, 2003, p. 99). Ela quer dizer que o que se chama de predisposições aponta na verdade a uma genealogia, as chamadas predisposições seriam os vestígios da história das proibições sexuais, de uma história não contada, mas cujos efeitos aparecem. 
Butler comenta que para Lévi-Strauss é o tabu do incesto que cria um nexo entre a antropologia estrutural e a psicanálise, e embora este antropólogo não credite Totem e tabu (Freud, 1976 [1913]) a uma verdade empírica, reconhece seu valor mítico. Butler traz a seguinte citação de Lévi-Strauss: "o desejo pela mãe ou irmã, o assassinato do pai e o arrependimento dos filhos indubitavelmente não correspondem a nenhum fato ou grupo de fatos a ocupar um dado lugar na história. Mas talvez expressem um sonho antigo e vivedouro" (Lévi-Strauss apud Butler, 2003, p. 70).

Butler critica Lévi-Strauss por dizer que estes desejos correspondem a fantasias inconscientes que nunca se realizam. Parece que Butler está pensando num plano de realidade, enquanto Lévi-Strauss fala de um plano de realidade psíquica. De fato, para a psicanálise o incesto está interditado porque não é possível voltar a constituir Um com a mãe, desde que se constitui a alteridade, desde que se funda o sujeito e não porque não seria possível deitar com a mãe. Há uma diferença entre a instauração da lei paterna na subjetividade e a lei patriarcal na cultura. Butler questiona como se constrói essa interdição à heterossexualidade incestuosa, apontando novamente a agência masculina. Parece desconsiderar que também a menina não pode reintegrase à mãe (ou formar Um) e que esta impossibilidade não depende do sexo da criança (Butler, 2003, p. 72).

Do ponto de vista da antropologia, Butler interroga se não seria possível outra estruturação de parentesco, que não redundasse no tabu do incesto, na exogamia e consequente binarismo sexual e invisibilidade dos gêneros que não correspondem à heteronormatividade. $\mathrm{Na}$ antropologia estrutural proposta por Lévi-Strauss as mulheres são o objeto de troca que consolida a relação entre clãs patrilineares. A mulher permutada é o termo relacional entre grupos de homens: "ela não tem uma identidade, e tampouco permuta uma identidade por outra. Ela reflete a identidade masculina, precisamente por ser o lugar da ausência” (Butler, 2003, p. 66). As mulheres são e não são o signo patronímico, pois são excluídas do próprio sobrenome que carregam. Elas não possuem uma identidade própria, mas apenas uma identidade relacional, identidade da relação entre homens. Esta estruturação distribui identidades aos homens e falta de identidade às mulheres, diz Butler. Sendo o tabu do incesto e a regra da exogamia o que articula psicanálise e antropologia estrutural, e resultando destes dois eixos o lugar visível e central do homem e o apagamento das mulheres, ambas as teorias são consideradas falocêntricas. Butler cita Lévi-Strauss: "o surgimento do pensamento simbólico deve ter exigido que as mulheres, como as palavras, fossem coisas a serem trocadas" (Butler, 2003, p. 69).

Butler e outras feministas interrogam-se se seria possível pensar o simbólico desde outra perspectiva que não a estruturalista. Essa busca seria uma tentativa de poder descobrir alguma forma de alterar o próprio modo de funcionamento da linguagem, pensada dentro da perspectiva da linguística estrutural, que operando por um sistema de oposições, sustentaria a diferença sexual e a opressão feminina. Nesta perspectiva dedica um capítulo de seu livro Problemas de Gênero a debater as teorizações de Julia Kristeva. Kristeva é uma psicanalista, escritora e feminista búlgaro-francesa, que propõe pensar para além do simbólico, como uma via de libertação deste sistema patriarcal de parentesco e subjetivação. Uma de suas proposições é a retirada da língua do lugar de objeto central da linguística, colocando o sujeito em processo em seu lugar. Esta autora faz críticas à estrutura rígida da ordem simbólica e afirma que se as mulheres pudessem sair desta ordem poderiam expressar-se livremente, enquanto sujeitos fora de um sistema de oposições binárias, o que afetaria as questões de gênero e da diferença sexual (Clarke, 1999).

Segundo Butler (2003), Kristeva aponta a semiótica como alternativa ao simbólico. A semiótica entendida como aquilo que expressa a multiplicidade libidinal original, o campo da linguagem poética, no qual proliferam os significados diversos, múltiplos e a semântica em aberto. Essa linguagem poética seria o reencontro com o corpo materno, que subverteria a lei paterna. Como se pode verificar tratar-se-ia de uma estratégia feminista para fugir do simbólico, entendido como aquilo que reproduz a opressão feminina e a heterossexualidade. Butler faz críticas a essa hipótese de Kristeva, afirmando que sua teoria depende da estabilidade e da reprodução da lei paterna, pois Kristeva diz que a presença continuada da subversão pode levar à psicose. Também ao afirmar que o corpo materno seria portador de um conjunto de significados anteriores à própria cultura, ela, aos olhos de Butler, reafirmaria a função paterna como fundadora da cultura. 
Não é também nas teorizações de Julia Kristeva que Butler vai encontrar a saída que busca. Mas é inegável o quanto recorre aos psicanalistas e a suas teorizações para compreender a subjetividade e assim encontrar meios de produzir efeitos na cultura que pudessem alterar as estruturas rígidas de gênero, a heteronormatividade e o patriarcalismo.

A concepção de gênero como ato performativo em Problemas de gênero (2003) foi o foco de muitos debates e retomadas do conceito em seus livros posteriores.

"Considerada coletivamente, a prática repetida de nomear a diferença sexual criou essa aparência de divisão natural. A "nomeação" do sexo é um ato de dominação e coerção, um ato performativo institucionalizado que cria e legisla a realidade social pela exigência de uma construção discursiva/perceptiva dos corpos, segundo os princípios da diferença sexual” (Butler, 2003, p. 168).

É da obra How to do things with words de Austin, que Judith Butler vai retirar seu conceito de ato performativo (Porchat, 2014). Nesta obra, Austin classifica dois tipos de atos de fala: os constatativos e os performativos. Os performativos seriam estes atos de fala que criam aquilo que nomeiam. Estes interessam Butler pela possibilidade que lhe oferecem para pensar a questão do gênero. Além disso, o repúdio dos corpos em função de seu sexo, suas práticas sexuais ou sua cor, fundam territórios de sexualidades, práticas e raças hegemônicas. A isso Butler, acompanhando Foucault, nomeia de produção disciplinar de gênero, que visa a regulação heterossexual e o ocultamento das descontinuidades e incoerências de gênero. Mas a desregulação e a descontinuidade entre gênero, sexualidade e desejo, a desagregação e desorganização do campo dos corpos mostram que a regulação heterossexual não passa de uma ficção. Entretanto, como se fantasia uma certa coerência de identidade, atos, gestos e desejos, diz Butler, produzem o efeito de uma certa substancia interna, que sugerem, mas nunca revelam.

"Esses atos, gestos e atuações, entendidos em termos gerais, são performativos, no sentido de que a essência ou identidade que por outro lado pretendem expressar são fabricações manufaturadas e sustentadas por signos corpóreos e outros meios discursivos. O fato de o corpo gênero ser marcado pelo performativo sugere que ele não tem status ontológico separado dos vários atos que constituem sua realidade" (Butler, 2003, p. 194).

A noção de uma identidade de gênero, mulher, por exemplo, é parodiada em práticas como o travestismo, segundo Butler. Mas ela ressalta que a imitação não presume a existência de um original. E acrescenta, o gênero é performativo, não tem o caráter de estável, mas pela repetição estilizada de atos dá a ilusão de um eu permanentemente marcado pelo gênero. A aparência de substância é uma realização performativa em que a plateia e os próprios atores passam a acreditar. E sendo assim, para ela não faz sentido medir, qualificar ou regular as verdadeiras configurações de gênero, exceto pela intenção de preservar a heterossexualidade e a dominação masculina.

\section{Márcia Arán: Seria a PSICANÁlise um dispositivo de SEXUALIDAde QUE PERDEU SEU CARÁTER SUBVERSIVO?}

Márcia Arán foi uma psicanalista feminista, com experiência nas áreas de Saúde Coletiva, Psicologia e Psicanálise, professora do Instituto de Medicina Social da Universidade Estadual do Rio de Janeiro (UERJ), onde coordenou a linha de pesquisa Gênero, Subjetividade e Biopolítica. Com atuação clínica, estabeleceu importantes discussões com as teorizações psicanalíticas freudo-lacanianas do feminino e da diferença sexual.

Para ela, as formulações da sexualidade em psicanálise, ainda que fundadas nos conceitos de inconsciente e pulsão, são sempre históricas e contingentes. Freud, ao longo de toda sua obra reformulou diversas vezes suas teorizações sobre a sexualidade infantil, sobre o Édipo e a sexualidade feminina. Lacan também o fez, tendo pensado a sexualidade e a sexuação de maneiras diversas. Diante disto, Arán afirmava ser uma necessidade ética e política e uma tarefa muito importante repensar a sexualidade na atualidade (Arán, 2009). Arán elencou um conjunto de mudanças na cultura, que produziram deslocamentos nos lugares dos 
homens e das mulheres e que, segundo ela, certamente construíram um novo conjunto de valores, impressões e referências para compreender a diferença sexual, tais como a escolarização das mulheres, entrada no mercado de trabalho, crise da família burguesa, visibilidade da homossexualidade e mudanças corporais realizadas por transgêneros, transexuais e intersexuais.

Estes fenômenos redundaram na passagem da estruturação social apoiada na família tradicional para novas modalidades de laço, juridicamente estabelecidas. Arán interrogava em que medida a psicanálise seria um dispositivo $^{7}$ da sexualidade que, tendo perdido seu caráter subversivo, operaria restaurando a diferença sexual a partir das premissas da heterossexualidade e da opressão sexual masculina sobre as mulheres e minorias. Para tanto revisitou os Três ensaios sobre a teoria da sexualidade, texto freudiano de 1905 já referido, e também as concepções lacanianas da diferença sexual, incluindo as fórmulas da sexuação.

De acordo com Arán, inicialmente a psicanálise teria subvertido as noções tradicionais afirmando a existência da sexualidade infantil, apontando a possibilidade de variação do objeto, desligando a sexualidade da finalidade de procriação, entendendo toda a sexualidade como perversa, sendo a neurose apenas o negativo da perversão. Neste momento inaugural, a psicanálise efetivamente teria derrubado a proposição normativa de uma sexualidade essencialmente reprodutiva que vigorava no saber médico do século XIX.

A sexualidade, dita perverso-polimorfa, seria reprimida a partir dos recortes constituídos no período de latência, período que se inicia com a saída do complexo de Édipo. Arán ressalta que em sua compreensão, foi apenas a partir da releitura lacaniana, com a teorização da metáfora paterna que o Édipo passou a implicar propriamente "um processo de acesso ao simbólico, pelo qual a criança vai se constituir como sujeito, mediante a operação inaugural da metáfora paterna e seu mecanismo correlativo, o recalque originário da 'coisa' materna" (Arán, 2009, p. 657). Para ela, essa teorização de Lacan é o que vai situar o pai como relacionado à ideia de cultura, já que é em relação à função paterna que se constitui tanto o ideal do eu, quanto a conexão entre normatização libidinal e cultural. Esta teorização lacaniana vai, de acordo com Arán, sustentar o sistema - a mãe, depois o pai - como um ordenamento psíquico universal, apoiado justo numa visão tradicional de papeis masculinos e femininos. Este é um ponto de incômodo na psicanálise lacaniana para Arán. Apesar das afirmações de que homem e mulher tem um significado muito particular para a psicanálise, principalmente a partir do Seminário 20: Mais, ainda (Lacan, 2008 [1972-1973]) inúmeras vezes as explicações das argumentações dadas por Lacan e outros psicanalistas, como Jacques-Alain Miller (2009), recaem no binômio homem - mulher. É o que podemos verificar em seu comentário no artigo $A$ psicanálise $e$ o dispositivo da diferença sexual, fazendo referência à teoria do Nome-do-pai.

Arán entende que os conceitos de identificação e sexuação na psicanálise restringem as manifestações da sexualidade somente a duas posições normativas: masculino e feminino e que o simbólico construído nesta base estruturalista limita as possibilidades de novas configurações de gênero e laços sociais.

\footnotetext{
"Em linhas gerais, a teoria psicanalítica oficial oscila entre descrever a sexualidade feminina a partir da dialética de ter ou não o pênis-falo - em que necessariamente a mulher só pode ser concebida como um sujeito marcado pela sua inferioridade -, e situá-la no registro da não existência. Como vimos (...), para Freud, o destino da sexualidade feminina é a inveja do pênis, tendo na sua versão positiva a maternidade e na negativa a renúncia e a virilização. Já para Lacan, considerando-se as suas fórmulas de sexuação, o lado feminino acaba sendo um limite interno ao masculino, onde a mulher aparece como "não-toda" inscrita na função fálica. A própria escolha do falo como significante do desejo significa uma posição sexuada de quem só pode conceber o feminino a partir da exclusão. $\mathrm{O}$ que se observa nesse contexto é uma espécie de versão psicanalítica para o modelo da dominação masculina em que, como diz Lacan, 'a mulher não existe” (Arán, 2009, p.659).
}

Como podemos ver, as teóricas feministas, mesmo as psicanalistas envolvidas em prática clínica, têm significativos questionamentos a conceituações psicanalíticas, relacionadas principalmente, e ainda, às questões das diferenças sexuais, do falo como significante universal com suas consequências na secundarização do feminino; velhas questões sobre novas formas de subjetivação no contemporâneo, com exigências de novas respostas. 
Queremos retomar e enfatizar algumas questões, reforçando inicialmente que as funções de pai e mãe não estão necessariamente articuladas a quem quer que seja, exceto àqueles que por contingência colocam estas funções em operação, que podem ser quaisquer pessoas, observando ainda que frequentemente é a pessoa que exerce a função materna quem coloca em cena a função paterna, pelo simples fato de desejar além da criança, de não deixar de desejar apenas por estar com a criança. O discurso de inferioridade feminina não pode ser tomado literalmente sem considerar a presença/ausência do pênis como uma representação metafórica da completude da mãe, da mãe que é reconhecida como fálica pelas crianças de ambos os sexos no primeiro momento do Édipo, momento em que a criança é equivalente ao falo (materno), sendo o falo o representante daquilo que a mãe deseja, a criança, metáfora do falo. É quando a mãe deseja além da criança, que a criança é desalojada do lugar de falo, ou seja, descobre que não é o falo materno e, ao mesmo tempo, descobre que a mãe é castrada, pois deseja. A mãe cai de um lugar suposto completo e, a partir daí, tendo a criança descoberto que não é o falo, recalca este saber no caso da constituição neurótica e vai supor que o desejo materno se dirige para algo ou alguém que porte o falo, "a ponto de Lacan ter podido fazer do desejo de ser o falo a fórmula constante do desejo neurótico” (Miller, 2014, p. 7).

$\mathrm{Na}$ verdade, a psicanálise vai dizer que ninguém é ou tem o falo, mas é possível escolher uma posição de semblante de ter ou não ter o falo, a estes semblantes a psicanálise nomeia homem e mulher. Estas são duas posições possíveis em relação ao significante do falo. Duas respostas frente à experiência da castração. E neste caso, a mulher não está situada em posição superior ou inferior, mas nos seres castrados é possível escolher uma maneira de recalcar a castração obtendo um falo por duas vias: ser o falo ou ter o falo. Ee nesta perspectiva que o semblante mulher representa a ausência de falo. Trata-se apenas de uma estratégia neurótica para recalcar a castração simbólica, esta que atinge a todos. Mas como para Lacan a castração simbólica opera para todos que um dia descobriram não ser suficientes para obstruir o desejo materno, ela, a castração, também vai aparecer do lado daqueles que se situam na posição masculina. Parece que não encontramos de fato em Lacan o que possa ser nomeado de inferioridade, mas apenas neuróticos que quando confrontados com a castração lançam mão de estratégias para fazê-la desaparecer.

Lacan vai dizer nas fórmulas da sexuação, que aqueles que se situam do lado mulher não estão totalmente submetidos à norma fálica, o que significa dizer que não estão completamente submetidos à castração. Diferente do entendimento de Arán, os que estão do lado homem das fórmulas são justamente os castrados, os que têm seu gozo totalmente submetido à norma fálica. A afirmação "A mulher não existe" (Lacan, 2009 [1971], p. 69) aponta ao fato de que do lado mulher não se trata uma totalidade, mas que as mulheres têm que ser consideradas uma por uma.

\section{Concluindo}

Os estudos feministas inicialmente e depois os estudos de gênero sempre estiveram alinhados com movimentos de busca da ampliação e inclusão das diversidades, daqueles que eram invisibilizados por suas sexualidades "desviantes" e/ou ditas abjetas. Fruto desta luta surgiram diálogos com a psicanálise desde Freud, pois a psicanálise oferecia ferramentas para pensar a constituição da subjetividade, os processos de submissão e de identificação a padrões de gênero.

Nestes diálogos houve muitos encontros, que aconteciam sempre que os conceitos e teorizações psicanalíticas contribuíam para trazer luz sobre os processos de subjetivação das identidades de gênero, bem como dos processos de submissão, principalmente naquilo que era interpretado como o reforçamento da matriz disciplinar heterossexual. Butler, Rubin e Arán buscavam encontrar nesta compreensão da constituição subjetiva meios que possibilitassem a construção de estratégias para provocar mudanças na cultura patriarcal heteronormativa.

A psicanálise concorreu para a compreensão de que o problema das exigências hegemônicas da cultura não estava apenas no exterior, mas nas próprias subjetividades. Por outro lado, havia desencontros fruto 
de compreensões dissonantes referentes a conceitos como diferença sexual, fálico/castrado, homem-mulher. Estes intercâmbios foram ricos para ambas as partes. Os estudos de gênero encontraram elementos para pensar suas questões na psicanálise, e as reflexões e críticas daqueles estudos levaram a avanços e reformulações da psicanálise.

\section{REFERENCIAS BIBLIOGRÁFICAS}

Arán, M. (2009). A psicanálise e o dispositivo diferença sexual. Revista Estudos Feministas, 17(3), 653-673. Recuperado de: https://periodicos.ufsc.br/index.php/ref/article/view/S0104-026X2009000300002

Brousse, M-H. (2016). Las identidades, uma politica; la identificacion, um processo; la identidade um sintoma. Recuperado de: http://identidades.jornadaselp.com/textos-y-bibliografia/texto-de-orientacion/las-identidades -una-politica-la-identificacion-un-proceso-y-la-identidad-un-sintoma/

Butler, J. (2001). Mecanismos psíquicos del poder: teorias sobre la sujeción. Madrid: Ediciones Cátedra.

Butler, J. (2003). Problemas de gênero: feminismo e subversão da identidade. Rio de Janeiro: Editora Civilização Brasileira.

Cesarotto, O. \& Leite, M. (1993). Jacques Lacan: uma biografia intelectual. São Paulo: Iluminuras.

Dafunchio, N. S. (2008). Confines de la psicosis: Teoría y práctica. Buenos Aires: Del Bucle.

Foucault, M. (1988). História da Sexualidade I. A vontade de saber. Rio de Janeiro: Edições Graal.

Freud, S. (2010 [1905]). Três Ensaios sobre a teoria da sexualidade. In Obras Completas (v.6). São Paulo: Companhia das Letras.

Freud, S. (1976 [1910]). Leonardo da Vinci e uma lembrança de sua infância. In Edição Standard das Obras Completas de Sigmund Freud. Rio de Janeiro: Imago.

Freud, S. (1976 [1917]) Luto e melancolia. In Edição Standard das Obras Completas de Sigmund Freud. Rio de Janeiro: Imago.

Freud, S. (1976 [1925]). Algumas consequências psíquicas da diferença anatômica entre os sexos. In Edição Standard das Obras Completas de Sigmund Freud. Rio de Janeiro: Imago.

Freud, S. (1976 [1933]) A feminilidade. In Edição Standard das Obras Completas de Sigmund Freud. Rio de Janeiro: Imago.

Knudsen, P. P. (2010). Conversando sobre psicanálise: entrevista com Judith Butler. Revista Estudos Feministas, 18(1). Recuperado de https://periodicos.ufsc.br/index.php/ref/article/view/S0104-026X2010000100009/12393

Lacan, J. (1992 [1969-1970]). Seminário, livro 17. O avesso da psicanálise. Rio de Janeiro: Jorge Zahar.

Lacan, J. (1998). De uma questão preliminar a todo tratamento da psicose. In V. Ribeiro (tr.), Escritos. Rio de Janeiro: Jorge Zahar.

Lacan, J. (2008 [1973]). Seminário, livro 20: Mais ainda. Rio de Janeiro: Jorge Zahar.

Lacan, J. (2009 [1971]). Seminário, livro 18: De um discurso que não fosse de semblante. Rio de Janeiro: Jorge Zahar.

Lago, M. (2010). A psicanálise nas ondas do feminismo. In Rial, C.; Pedro, J.y Arend, S. (Orgs.) Diversidades: dimensões de gênero e sexualidade. Ilha de Santa Catarina: Mulheres.

Miller, J. (2011). Intuições milanesas. Op̧̧ão Lacaniana online nova série, 2(5). Recuperado de http://www.opcaolaca niana.com.br/pdf/numero_5/Intui\%C3\%A7\%C3\%B5es_milanesas.pdf

Miller, J. (2014). A criança entre a mulher e a mãe. Opção Lacaniana online nova série, 5(15). Recuperado de http://w ww.opcaolacaniana.com.br/pdf/numero_15/crianca_entre_mulher_mae.pdf

Piscitelli, A. (2002). Recriando a (categoria) mulher? In L. Algranti (Org.). A prática feminista e o conceito de gênero. Campinas: IFCH/Unicamp.

Porchat, P. (2014). Psicanálise e transexualismo. Desconstruindo gêneros epatologias com Judith Butler. Curitiba: Juruá.

Rubin, G. \& Butler, J. (2003). Tráfico sexual: entrevista. Cadernos Pagu, 21, 157-209. Recuperado de http://www.s cielo.br/pdf/cpa/n21/n21a08.pdf 
Rubin, G. (2017 [1975]). O tráfico de mulheres: notas sobre a economia política do sexo. Recife: SOS Corpo. Recuperado de https://repositorio.ufsc.br/handle/123456789/1919

Saraiva, E. (2007). Conjugando amor e desejo: experiências masculinas do "assumir-se" homossexual. Florianópolis: PPGICH, UFSC.

Virmond Vieira, J. \& Angonese, M. (2016). Clínica dos gêneros não inteligíveis: Judith Butler e psicanálise. Revista Estudos Feministas, 24(1), 369-372.

Virmond Vieira,J. (2018). A plasticidade na eleição de parcerias sexuais em tempos de queda do falocentrismo (Tese de doutoramento). Programa de Pós-graduação em Psicologia da Universidade Federal de Santa Catarina (PPGP UFSC), Florianópolis, Brasil. Recuperado de http://repositorio.ufsc.br/bitstream/handle/123456789/198149 /PPSI0818-T.pdf

\section{Notas}

1 Este artigo foi elaborado a partir de um capítulo da tese de doutoramento intitulada Plasticidade na Eleição de Parcerias Sexuais em Tempos de Queda do Falocentrismo, defendida pela primeira autora no Programa de Pós-Graduação em Psicologia da Universidade Federal de Santa Catarina (PPGP-UFSC) em 2018, sob orientação da segunda autora.

2 Freud vai alegar que uma das consequências psíquicas da diferença anatômica entre os sexos é a inveja do pênis por parte das meninas. Diz Freud que nas brincadeiras as meninas descobrem que o pênis dos meninos é visível e de grandes proporções e comparam-no ao seu clitóris, este pequenino e quase invisível e que isto lhes provoca inveja do pênis. Esta inveja vai estar correlacionada a um sentimento de inferioridade em relação aos homens.

3 De acordo com Nieves Dalfunchio (2008) em Confines de la psicosis, a clínica de Lacan pode ser dividida em quatro momentos. Tendo acedido à psicanálise a partir da psiquiatria, dedica-se ao registro do imaginário (I) para compreender a derrocada imaginária na psicose num primeiro momento. Num segundo momento, que se inicia no quarto ano de seus seminários, dedica-se a compreender o que fracassa no registro simbólico $(S)$ e provoca a derrocada imaginária da psicose. Estuda como seria o simbólico, a estrutura da linguagem e os efeitos do simbólico no imaginário. Nesta etapa conclui que há primazia do simbólico sobre o imaginário e teoriza a metaforização do Nome-do-pai como condição de estruturação da neurose. É com este Lacan que Rubin debate. Há um terceiro tempo, quando Lacan percebe que a operação simbólica da constituição subjetiva deixa um resto real, que vai nomear de objeto a. É nos seminários 11 a 18 que debate as consequências teóricas e clínicas deste resto real. A partir do seminário 18 começa a construir as fórmulas da sexuação, que o levam à topologia, onde começa a cair a primazia do simbólico e teoriza a equivalência entre os três registros I, S e R.

4 Tivemos acesso à versão espanhola, por isso nas citações manteremos a língua em que lemos o texto.

5 Posição do inconsciente é um artigo no qual Lacan articula as duas operações de causação do sujeito: alienação e separação.

6 De acordo com Porchat (2014), o filósofo Slavoj Zizek faz algumas críticas ao uso impreciso de conceitos por Butler que, em seu entender, não distinguiria diferentes concepções de alguns autores.

7 Em História da sexualidade (1988), Foucault afirma que o dispositivo está sempre inscrito em um jogo de poder, estando sempre ligado a uma ou mais configurações de saber que dele nascem, mas que também o condicionam. E enfatiza que é isto, o dispositivo: estratégias de relações de força sustentando tipos de saber e sendo sustentadas por eles. 